\title{
RANKL directly induces bone morphogenetic protein-2 expression in RANK-expressing POS-1 osteosarcoma cells
}

\author{
YOHANN WITTRANT ${ }^{1}$, FRANçOIS LAMOUREUX ${ }^{1}$, KANJI MORI $^{1}$, ANNE RIET $^{1}$, \\ AKIRA KAMIJO $^{2}$, DOMINIQUE HEYMANN ${ }^{1}$ and FRANçOISE REDINI ${ }^{1}$ \\ ${ }^{1}$ Université de Nantes EA 3822, INSERM ERI 7, Physiopathologie de la Résorption Osseuse et Thérapie des \\ Tumeurs Osseuses Primitives, Faculté de Médecine, 1 rue Gaston Veil, 44035 Nantes cedex 1, France; \\ ${ }^{2}$ Department of Orthopaedic Surgery, Yokohama City University, School of Medicine, \\ 3-9 Fukuura, Kanazawa-ku, Yokohama 236-0004, Japan
}

Received August 16, 2005; Accepted September 27, 2005

\begin{abstract}
The POS-1 murine model of osteolytic osteosarcoma was used to elucidate the molecular and cellular mechanisms involved in the development of primary bone tumors and associated lung metastasis. The POS-1 cell line is derived from an osteosarcoma tumor which develops spontaneously in $\mathrm{C} 3 \mathrm{H}$ mice. The POS-1 cell line was characterized in vitro by mineralization capacity and expression of bone markers by semi-quantitative RT-PCR, compared to primary osteoblasts and bone marrow cells. POS- 1 cells showed no mineralization capacity and exhibited an undifferentiated phenotype, expressing both osteoblastic and unexpected osteoclastic markers (TRAP, cathepsin K and RANK). Thereby, experiments were performed to determine whether RANK was functional, by studying the biological activity of murine RANKL through the receptor RANK expressed on POS-1 cells. Results revealed a RANKL-induced increase in ERK phosphorylation, as well as BMP-2 induction at the mRNA and protein levels, and a decrease of POS-1 cell proliferation in the presence of $10 \mathrm{ng} / \mathrm{ml}$ RANKL. BMP-2 induction is dependent on the ERK 1/2 signal transduction pathway, as its expression is abolished in the presence of UO126, a specific synthetic inhibitor of the ERK 1/2 pathway. Moreover, a 2-fold molar excess of soluble RANK blocks the RANKL-induced BMP-2 expression, demonstrating that the biological effects of RANKL observed in POS-1 cells are mediated by RANK. This is the first report describing a functional RANK expressed on osteosarcoma cells, as shown by its ability to induce signal transduction pathways and biological activity when stimulated by RANKL.
\end{abstract}

Correspondence to: Dr Françoise Redini, Université de Nantes EA 3822, INSERM ERI 7, Physiopathologie de la Résorption Osseuse et Thérapie des Tumeurs Osseuses Primitives, Faculté de Médecine, 1 rue Gaston Veil, 44035 Nantes cedex 1, France

E-mail: francoise.redini@univ-nantes.fr

Key words: osteosarcoma, bone tumors, RANK, RANKL, BMP-2

\section{Introduction}

Osteosarcomas (OS), the most frequent primary bone tumor that develops mainly in the young, the median age of diagnosis being 18 years, are classified into several subgroups according to their localisation and histology (1). The unifying histological feature present in all types and subtypes of OS is the presence of osteoid produced by neoplastic cells (2). The origin of osteosarcoma is not fully understood, as the tumor cells may have different origins depending on the dominant histological element. A preference for pulmonary metastases compared with other metastatic sites is a distinct feature of osteosarcoma, and 5-year survival rates after the detection of lung metastasis are less than $30 \%$ (3). Despite recent improvements in chemotherapy and surgery, the problem of non-response to chemotherapy remains and current strategies for the treatment of high-grade osteosarcoma fail to advance in its prognosis. Therefore, the developments of new therapies are needed.

Osteoprotegerin (OPG), the receptor activator of NF- $\mathrm{NB}$ (RANK) and RANK ligand (RANKL) are the main molecules involved in the regulation of bone metabolism (reviewed in ref. 4). In the case of bone tumors, Grimaud et al demonstrated an increase in the RANKL:OPG ratio in the serum of patients with high-grade osteosarcoma (5), suggesting that the molecular triad, OPG/RANK/RANKL, might play a crucial role in tumorigenic osteolysis. RANKL augmentation directly produced by tumor cells (6) or indirectly via osteoblasts (7) contributes not only to an increased bone resorption but also to the release of growth factors stored in the bone matrix, creating a suitable context for tumor expansion as they increase tumor cell proliferation (8). In addition, it has been reported that tumor cell proliferation is often followed by a loss of differentiation markers or adhesion molecules, such as integrins, allowing the spreading of tumor cells to other organs leading to metastasis (9).

To elucidate the molecular and cellular mechanisms involved in the development of primary bone tumors and associated lung metastasis, the POS-1 murine model of osteosarcoma was used. The POS-1 cell line is derived from osteosarcoma which developed spontaneously in $\mathrm{C} 3 \mathrm{H}$ mice. The tumor can be successfully transplanted in $\mathrm{C} 3 \mathrm{H}$ mice or 
POS-1 cells inoculated into the hind footpad of mice and shows spontaneous metastasis to the lungs (10). Tumors were first recognized macroscopically at 2 weeks after inoculation and developed in more than $90 \%$ of inoculated mice at 5 weeks, lung metastasis being observed in all mice that developed tumors.

In this study, the in vitro phenotype of the POS- 1 cell line was compared to those of the primary murine osteoblasts and bone marrow cells, in terms of mineralization capacity and bone marker expression. POS-1 cells exhibit an undifferentiated phenotype as they express osteoblastic and surprisingly osteoclastic markers, such as tartrate resistant acid phosphatase (TRAP), cathepsin K (Cat K) and RANK. Data from the literature reported the involvement of RANKL, either directly expressed by tumor cells themselves (6) or indirectly by osteoblasts or bone stromal cells (7), in bone tumor progression. In the osteolytic tumor-bone 'vicious cycle' described for bone metastasis from breast carcinoma (8), RANKL may mediate the release of growth factors from bone matrix and the production of growth factors, cytokines or chemokines by the activated osteoclast, or it may directly induce the production of angiogenic, invasion, chemoattractant and osteotropic factors by RANK positive cells. The influence of murine RANKL was therefore determined to see whether RANK may act as a functional receptor at the surface of osteosarcoma cells. The potential biological activity of RANKL was assayed on POS-1 cells in terms of phenotype modulation, signalling pathway and cell proliferation.

\section{Materials and methods}

Cell culture. The murine osteosarcoma cell line, POS-1, derived from osteosarcoma which spontaneously developed in mice was kindly provided by the Kanagawa Cancer Center (Kanagawa, Japan). The cells were cultured in RPMI-1640 medium (Bio Whittaker, Verviers, Belgium) supplemented with $10 \%$ fetal bovine serum (FBS, Dominique Dutscher, Brumath, France), at $37^{\circ} \mathrm{C}$ in a humidified atmosphere $(5 \%$ $\mathrm{CO}_{2} / 95 \%$ air). The cells were harvested at confluence with trypsin (0.5 g/l)/EDTA (0.2 g/1) (Cambrex BioSciences, Verviers, Belgium). Mouse macrophage precursors RAW 264.7 cells (obtained from Professor Matsumoto, Japan) were used as osteoclast-like cells as they are able to differentiate into multinucleated cells in the presence of RANKL (11). Bone marrow cells (BMC) and primary osteoblasts were isolated from $\mathrm{C} 3 \mathrm{H} / \mathrm{HeN}$ mice (IFFA-CREDO, L'Arbresles, France). Briefly, femora and tibiae were collected and minced in RPMI-1640 after the removal of soft tissue. Bone fragments were cultured as explants in one side, whereas bone marrow was cultured separately, to lead respectively to osteoblasts and bone marrow cell cultures, both cell types being cultured in RPMI-1640 medium supplemented with $10 \% \mathrm{FBS}$ and antibiotics, at $37^{\circ} \mathrm{C}$ in a humidified atmosphere.

RNA extraction and semi-quantitative RT-PCR analysis. POS- 1 cells and osteoblasts were seeded in a 6-well plate at a density of $10^{4}$ cells $/ \mathrm{cm}^{2}$ in RPMI-1640 supplemented with 10\% FBS. RAW 264.7 cells were seeded at the same density and maintained in phenol red-free $\alpha$-MEM supplemented $1 \%$ nonessential amino acids and 10\% FBS. At confluence, total
RNA was isolated from POS-1 cells, primary osteoblasts and the differentiated RAW 264.7 cells using TRIzol reagent (Invitrogen, Eragny, France). Total RNA were quantified by measuring the OD260 and integrity was checked by $1 \%$ agarose/formaldehyde gel electrophoresis. First, RNA was reversed-transcribed (RT), using $400 \mathrm{U}$ MMLV-RT from Invitrogen. To determine the expression of OPG, RANKL, collagen I (Coll I), osteocalcin (OC), Bone Sialo-Protein (BSP), bone morphogenetic protein-2 (BMP-2), core binding factor 1 (Cbfa1), RANK, calcitonin receptor (CTR), tartrate resistant acid phosphatase (TRAP) and cathepsin K (Cat K), two microliters of the RT reaction mixture were subjected to PCR using upstream and downstream primers (30 pmoles each, Table I) and $0.25 \mu 1$ of $5 \mathrm{U} / \mu 1$ Taq polymerase (Eurobio, Les Ulis, France). After the number of PCR cycles was increased, a plot was made for each sample, and the cycle values corresponding to the linear part of the amplification curve were determined (30 cycles for all primers, except 40 for CTR) and used to quantify the messages versus the $18 \mathrm{~S}$ signal determined in the same way (27 cycles). The PCR products were electrophoresed in $1 \%$ agarose gel containing ethidium bromide. The band densities were measured using the ImageQuant computer software program (Molecular Dynamics). The relative expression of each gene was calculated as the ratio to $18 \mathrm{~S}$ signal. Three independent experiments were performed for each gene and a representative experiment is shown in the Results section. To study the influence of RANKL on the POS-1 phenotype, mRNA expression was quantified in RANKL-treated POS-1 cells. When cells reached $70-80 \%$ confluence, they were washed and cultured in serumfree RPMI for 6 to $24 \mathrm{~h}$ in the presence of $1-200 \mathrm{ng} / \mathrm{ml}$ human soluble RANKL, kindly provided by Amgen Inc. (Thousand Oaks, USA). In a separate experiment, POS-1 cells were treated for $6 \mathrm{~h}$ with $100 \mathrm{ng} / \mathrm{ml}$ human RANKL preincubated for $1 \mathrm{~h}$ at room temperature with increasing concentrations of soluble human RANK (100-400 ng/ml, R\&D Systems).

Cell proliferation assays. POS-1 cells were seeded in a 96well-plate at a density of 2,800 cells per well, and cultured for $72 \mathrm{~h}$ in RPMI-1640 medium supplemented with $0.5 \%$ heat inactivated serum in the absence or presence of 1-200 ng/ml human soluble RANKL, or 1-100 ng/ml hBMP-2 (Abcys, Paris, France). The cell proliferation was determined by an XTTbased method, using the Cell Proliferation Kit II (Sigma, St. Quentin Fallavier, France) according to the supplier's recommendations. The OD was finally determined at $450 \mathrm{~nm}$ using a Wallac 1420 VICTOR $2^{\mathrm{TM}}$ multilabel counter (PerkinElmer, USA).

Mineralization assay. Mineralization assays were performed as previously described (12). Briefly, bone marrow cells and POS-1 cells were seeded in a 6-well plate at a density of $10^{4}$ cells/well, in RPMI-1640 medium supplemented with $10 \% \mathrm{FBS}$, in the absence or presence of $50 \mu \mathrm{g} / \mathrm{ml}$ ascorbic acid (Sigma) and $10^{-8} \mathrm{M}$ dexamethasone (Sigma). The medium was changed twice a week. After 7 days in culture, $10 \mathrm{mM}$ of $\mathrm{Na}$ - $\mathrm{B}$-glycerophosphate (Sigma) was added to each well in association with ascorbic acid and dexamethasone, and maintained in culture for 14 days. At the end of the incubation period, supernatant was removed and ice-cold ethanol was 
Table I. Oligonucleotide primers used for RT-PCR.

\begin{tabular}{|c|c|c|c|c|}
\hline Molecule & Primers & Strand & Size (bp) & $\begin{array}{c}\text { Conditions } \\
\text { (Tm, cycle number) }\end{array}$ \\
\hline \multirow[t]{2}{*}{ RANKL } & ACAGCGCTTCTCAGGAGTTC & + & 465 & $60^{\circ} \mathrm{C}$ \\
\hline & TGGACGCTAATTTCCTCACC & - & & 30 cycles \\
\hline \multirow[t]{2}{*}{ OPG } & TGACCAAGACACCTTGAAGG & + & 200 & $60^{\circ} \mathrm{C}$ \\
\hline & CTAGTTATAAGCAGCTTATT & - & & 30 cycles \\
\hline \multirow[t]{2}{*}{$\mathrm{OC}$} & TGACAAAGCCTTCATGTCCA & + & 174 & $60^{\circ} \mathrm{C}$ \\
\hline & TTTGTAGGCGGTCTTCAAGC & - & & 30 cycles \\
\hline \multirow[t]{2}{*}{ BSP } & GGGAGGCAGTGACTCTTCAG & + & 482 & $60^{\circ} \mathrm{C}$ \\
\hline & GTTCCTTCTGCACCTGCTTC & - & & 30 cycles \\
\hline \multirow[t]{2}{*}{ Coll I } & ATGACCAGGTTCACCTTTCG & + & 469 & $60^{\circ} \mathrm{C}$ \\
\hline & AAGAGGCGAGAGAGGTTTCC & - & & 30 cycles \\
\hline \multirow[t]{2}{*}{ Cbfa1 } & GGACCGTGGTTACCGTCAT & + & 242 & $60^{\circ} \mathrm{C}$ \\
\hline & ATGCGCCCTAAATCACTGAG & - & & 30 cycles \\
\hline \multirow[t]{2}{*}{ BMP-2 } & AGATCTGTACCGCAGGCACT & + & 458 & $60^{\circ} \mathrm{C}$ \\
\hline & TCTAAATGGGCCACTTCCAC & - & & 30 cycles \\
\hline \multirow[t]{2}{*}{ RANK } & AAGATGGTTCCAGAAGACGGT & + & 350 & $60^{\circ} \mathrm{C}$ \\
\hline & CATAGAGTCAGTTCTGCTCGGA & - & & 30 cycles \\
\hline \multirow[t]{2}{*}{ TRAP } & AАATCACTCTTTAAGACCAG & + & 316 & $60^{\circ} \mathrm{C}$ \\
\hline & TTATTGAATAGCAGTGACAG & - & & 30 cycles \\
\hline \multirow[t]{2}{*}{ CTR } & CTGCTCCTAGTGAGCCCAAC & + & 444 & $61^{\circ} \mathrm{C}$ \\
\hline & AGTGAGGAACAGCTAACGAC & - & & 40 cycles \\
\hline \multirow[t]{2}{*}{ Cat K } & GGGCCAGGATGAAAGTTGTA & + & 324 & $60^{\circ} \mathrm{C}$ \\
\hline & CCGAGCCAAGAGAGCATATC & - & & 24 cycles \\
\hline \multirow[t]{2}{*}{$18 \mathrm{~S}$} & TCAAGAACGAAAGTCGGAGGTTCG & + & 462 & $62^{\circ} \mathrm{C}$ \\
\hline & TTATTGCTCAATCTCGGGTGGCTG & - & & 27 cycles \\
\hline
\end{tabular}

'arimers are presented in a $5^{\prime}$ to $3^{\prime}$ orientation for the coding strand (+) and $3^{\prime}$ to $5^{\prime}$ for the non-coding strand (-). The product size generated by RT-PCR is indicated together with the experimental conditions used (Tm and cycle number corresponding to the linear part of the amplification curve used to quantify the messages versus the $18 \mathrm{~S}$ signal, determined in the same way). All the primers are against mouse molecules, except for RANKL (rat).

added to the wells for $1 \mathrm{~h}$. The cells were then washed twice with distilled water, and the presence of mineralized nodes was revealed by microscopic observation (Leica, DM IRB) using a $40 \mathrm{mM}$ alizarin red staining solution, $\mathrm{pH}$ 7.4. In a separate experiment, POS-1 cells were co-cultured with bone marrow under the same experimental conditions to determine whether POS-1 cells could interfere with the mineralization capacity of bone marrow cells.

Protein quantification and alkaline phosphatase assays. POS-1 cells were seeded in a 6-well plate at a density of $10^{4}$ cells/well and cultured as described above ( $\$$ Cell culture). After 96 h of culture, POS-1 cells were washed with PBS and lysed in ice-cold buffer [ $\mathrm{NaCl} 150 \mathrm{mM}$, Tris $50 \mathrm{mM}$, Nonidet P-40 1\%, sodium deoxycholate $0.25 \%, \mathrm{NaF} 1 \mathrm{mM}$, leupeptine $10 \mathrm{mg} / \mathrm{ml}$, aprotinin $10 \mathrm{mg} / \mathrm{ml}$, phenymethylsulfonylfluoride (PMSF) $0.5 \mathrm{mM}$, and glycerol 10\%]. The total amount of proteins for each sample was determined using a bicinchominic acid (BCA, Sigma) based method. Ten microliters of cellular lysis or standard BSA solution were added to $200 \mu 1$ of reagent (Copper II solution 1/50 diluted in bicinchominic acid) and incubated for $30 \mathrm{~min}$ at $37^{\circ} \mathrm{C}$. OD was determined at $570 \mathrm{~nm}$ as well as the protein concentration compared to the standard curve. The same amounts of proteins were used to perform alkaline phosphatase assays using Enzyline PAL kit according to the supplier's recommendations (BioMérieux, Marcy l'Etoile, France). At the end of the incubation period (10 min at room temperature), the reaction was stopped and OD was determined at $405 \mathrm{~nm}$ using a Wallac 1420 VICTOR $2^{\mathrm{TM}}$ multilabel counter.

Signal transduction analysis by Western blotting. POS-1 cells were seeded at a density of $10^{5}$ cells/well in a 6-well plate in RPMI-1640 supplemented with $10 \%$ FBS. When POS- 1 cells reached 70-80\% confluence, they were washed 3 times with RMPI-1640 and cultured in serum-free RMPI-1640 for $24 \mathrm{~h}$, then incubated for $1,2,5,10,15$ and $30 \mathrm{~min}$ in the absence or presence of $100 \mathrm{ng} / \mathrm{ml}$ human RANKL. POS-1 
cells were lysed in ice-cold buffer $(\mathrm{NaCl} 150 \mathrm{mM}$, Tris $50 \mathrm{mM}$, Nonidet P-40 1\%, sodium deoxycholate $0.25 \%$, NaF $1 \mathrm{mM}$, $\mathrm{NaVO}_{4} 1 \mathrm{mM}$, leupeptine $10 \mathrm{mg} / \mathrm{ml}$, aprotinin $10 \mathrm{mg} / \mathrm{ml}$, PMSF $0.5 \mathrm{mM}$, glycerol $10 \%$ ). The same amounts of proteins were resolved on $10 \%$ SDS-polyacrylamide gel electrophoresis (PAGE), and transferred to a polyvinydilene fluorure (PVDF) membrane (Millipore, Saint-Quentin en Yvelines, France). After washing twice with $0.05 \%$ Tween-20/PBS, the membrane was incubated in a saturating solution $(0.05 \%$ Tween-20/3\% BSA/PBS) for $30 \mathrm{~min}$ at room temperature with appropriate antibodies. The levels of phosphorylated and total forms of ERK1/2, IкB and p38 were detected by respective specific antibodies (Ozyme, Saint-Quentin en Yvelines, France, and R\&D) and revealed using the BM Chemiluminescence Western Blotting substrate (Roche Applied Science, USA). In another set of experiments, POS-1 cells were cultured in the presence of $25 \mu \mathrm{M}$ UO 126 (Calbiochem Merck, Fontenay-aux-Roses, France), a synthetic inhibitor of the ERK pathway to confirm the involvement of the ERK signalling pathway in RANKL-induced biological activity.

BMP-2 quantification. ELISA assay was used to quantify BMP-2 levels in culture supernatants of POS-1 cells treated or not with increasing concentrations of RANKL. Experiments were realized using the Human/Mouse/Rat BMP-2 Quantikine ELISA kit (R\&D Systems) according to the supplier's recommendations.

Caspase activity. POS-1 cells $\left(2 \times 10^{4}\right)$ grown in 24-well plates were treated with 1-100 ng/ml hBMP-2 for 24-72 h, washed once with PBS and lysed with $50 \mu 1$ of RIPA-buffer for $30 \mathrm{~min}$. The cells were then scraped off and the protein amount was quantified using the BCA (bicinchominic acid + Copper II sulfate) test (Pierce Chemical Co., Rockford, IL, USA). Caspase- 3 activity was assessed on $10 \mu 1$ of cell lysate with the CaspACE ${ }^{\mathrm{TM}}$ assay kit (Promega, Madison, WI, USA) following the manufacturer's recommendations. Cells treated with UV light for $30 \mathrm{sec}, 24 \mathrm{~h}$ before harvesting, were used as a positive control for caspase activity.

In vivo characterization of osteosarcoma induced by POS-1 cell inoculation. Four-week-old male $\mathrm{C} 3 \mathrm{H} / \mathrm{He}$ mice (IFFACREDO, L'Arbresle, France) were housed under pathogenfree conditions at the Experimental Therapy Unit (Medicine Faculty of Nantes, France), in accordance with the institutional guidelines of the French Ethical Committee and under the supervision of authorized investigators. POS-1 cells $\left(2 \times 10^{6}\right)$ were inoculated s.c. in the hind footpad of the mice. A tumor develops at the site of injection within three weeks that can be transplanted as a small fragment $\left(2 \times 2 \times 2 \mathrm{~mm}^{3}\right)$ in contact with the femora, leading to the development of a primary tumor and pulmonary metastases in three weeks. The tumor was then characterized by micro-architectural studies.

Micro-architectural quantification. Analysis of architectural parameters was performed using the high resolution X-ray micro-CT system for small animal imaging SkyScan-1072 (SkyScan, Aartselaar, Belgium). Relative volume (BV/TV) of the femora [total bone (cortical + trabecular) or trabecular
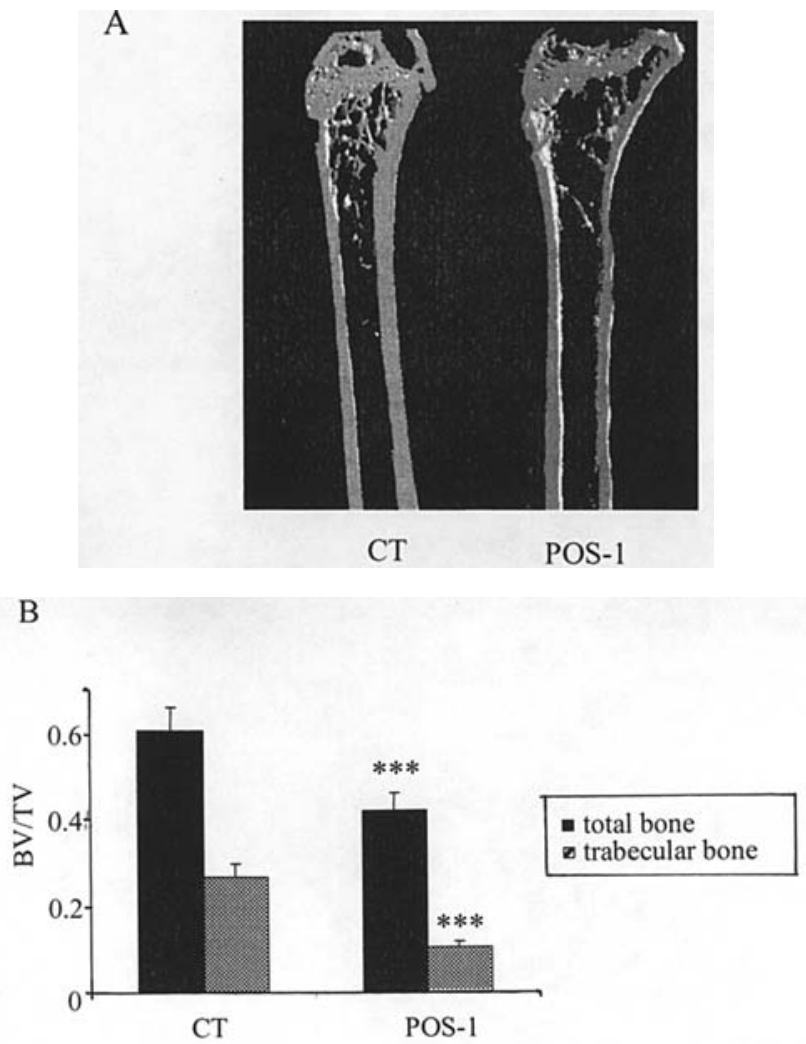

Figure 1. Micro-CT scans of mouse femora 4 weeks after implantation with POS-1 osteosarcoma as compared to controls. A, Hemi-sagittal sections of control (CT) and osteosarcoma (POS-1) femora are shown. B, Quantification of relative bone volume $(\mathrm{BV} / \mathrm{TV})$ of total and trabecular bone compared between controls (CT) and osteosarcoma-bearing mice (POS-1). ${ }^{* * * *} \mathrm{p}<0.005$.

bone] was quantified in the osteosarcoma group and compared to that of control mice.

Statistical analyses. Statistical evaluation of the in vitro proliferation data was performed by the ANOVA test. Results with $\mathrm{p}<0.05$ were considered significant.

\section{Results}

Characterization of osteosarcoma induced by POS-1 cell injection. After injection of $2 \times 10^{6}$ POS- 1 cells in the hind footpad of $\mathrm{C} 3 \mathrm{H} / \mathrm{He}$ mice, a primary tumor develops locally within approximately 21 days. This tumor can be re-grafted in contact with the femora, to see whether the primary tumor exhibits rather osteocondensant or osteolytic features. The tumor develops locally within two weeks. The mice were sacrificed 28 days post-implantation, and the femora were harvested and analysed for their microarchitectural parameters. The results presented in Fig. 1 demonstrate that the POS-1induced osteosarcoma is osteolytic as it reduces the cortical thickness and dramatically diminishes the relative trabecular bone volume, as quantified by $\mathrm{BV} / \mathrm{TV}=0.106$ versus 0.27 for the control $(-61 \%, \mathrm{p}<0.005)$ and total bone volume $(\mathrm{BV} / \mathrm{TV}=0.42$ versus 0.61 for the control, $-32 \%, \mathrm{p}<0.005)$.

POS-1 cells' characterization in vitro. POS-1 cells exhibit an undifferentiated phenotype, with expression of both osteo- 

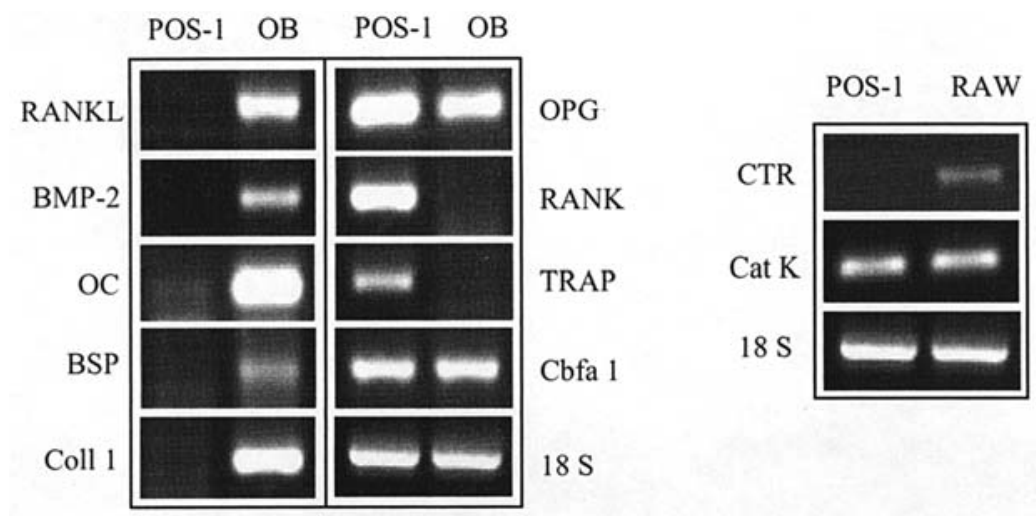

Figure 2. Bone marker expressed by POS-1 cells in vitro, as compared to mouse primary osteoblasts (OB) and mouse RAW 264.7 cells differentiated in osteoclast-like cells (RAW). The expression of several bone parameters, among them receptor activator of NF-кB ligand (RANKL), osteoprotegerin (OPG), osteocalcin (OC), Bone SialoProtein (BSP), type I collagen (Coll I), bone morphogenetic protein-2 (BMP-2), RANK, tartrate resistant acid phosphatase (TRAP), cathepsin K (Cat K), Core binding factor $\alpha 1$ (Cbfa1) and calcitonin receptor (CTR) was analysed in POS-1 cells by semi-quantitative RT-PCR according to the conditions described in Table I, and compared to osteoblasts or RAW 264.7 cells.

blastic and osteoclastic markers. Mature osteoblasts are characterised by the expression of phenotypic markers, including Coll I, OC, BSP, BMP-2, OPG, RANKL, and the transcription factor $\mathrm{Cbfa} 1$. The constant positive expressions of these markers were confirmed in the mouse osteoblasts tested in this study (Fig. 2). In comparison, semi-quantitative RT-PCR analysis showed that POS-1 cells do not express several osteoblastic markers, such as BMP-2, OC, BSP, Coll I and RANKL. However, the expression of Cbfa1 and OPG transcripts was still observed (Fig. 2). As osteosarcoma may be heterogeneous in its cell origin and composition, the expression of other markers was analysed, including osteoclastic cathepsin K, TRAP, CTR and RANK. Interestingly, POS-1 cells expressed Cat K, TRAP and RANK, but not CTR, which represents one of the most specific osteoclastic markers (Fig. 2). It can be concluded that POS-1 cells exhibit an undifferentiated phenotype, expressing markers from both osteoblastic and osteoclastic lineages.

POS-1 cells' biological activity in vitro. In addition to their phenotype, POS-1 cells were assessed for their capacity to demonstrate alkaline phosphatase activity and to induce mineralization nodules in vitro. Results presented in Fig. 3A show that POS-1 cells did not demonstrate any alkaline phosphatase activity as compared to primary osteoblasts. Bone marrow cells (BMC) isolated from $\mathrm{C} 3 \mathrm{H}$ mice contain osteoblastic cell precursors that can differentiate into mature osteoblasts when cultured with dexamethasone (12). Both cell types were incubated with ascorbic acid, dexamethasone and Na- $\beta$-glycerophosphate or not. After 21 days of culture, the results of alizarin red staining revealed that POS-1 cells were not able to form mineralization nodules in the presence of B-glycerophosphate, whereas BMC showed marked mineralization nodules (Fig. 3B). Moreover, the nodule formation induced in BMC alone was totally inhibited when POS-1 cells were co-cultured with bone marrow cells (not shown).

RANKL inhibits cell proliferation and induces BMP-2 expression in osteosarcoma POS-1 cells. As POS-1 cells express RANK, RANKL-induced biological activities were assayed to determine whether the receptor RANK is functional

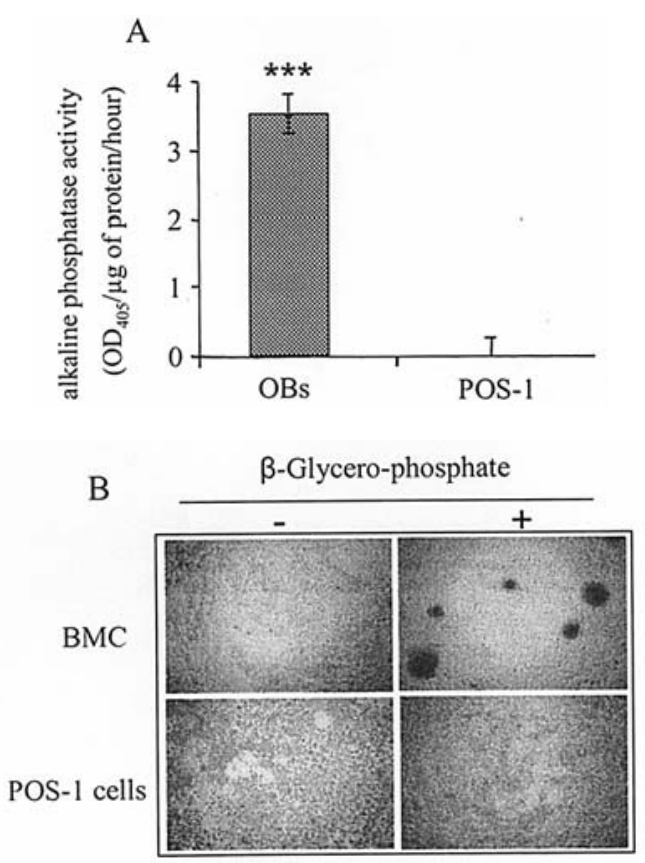

Figure 3. In vitro characterization of osteogenic properties of POS-1 cells. A, alkaline phosphatase activity in cell lysates of POS-1 cells and primary mouse osteoblasts (OBs) was performed using p-nitrophenyl phosphate as a substrate and corrected for protein content. The results are presented as the OD value measured at $405 \mathrm{~nm}$ per $\mu \mathrm{g}$ of protein per hour. ${ }^{* * *} \mathrm{p}<0.005$. $\mathrm{B}$, mineralized nodule formation in POS-1 cells. POS-1 cells and bone marrow cells (BMC) were cultured in a medium containing $50 \mu \mathrm{g} / \mathrm{ml}$ ascorbic acid, $10 \mathrm{mM} \mathrm{Na} ß$-glycerophosphate, $10^{-8} \mathrm{M}$ dexamethasone for 21 days. Typical alizarin red- $\mathrm{S}^{+}$nodules were observed in phase contrast microscopy. Magnification x200.

on osteosarcoma cells and could mediate biological activity. First, the effects of RANKL were studied on POS-1 cell proliferation after $72 \mathrm{~h}$ of culture. Using an XTT-based method, 1-200 $\mathrm{ng} / \mathrm{ml}$ hRANKL decreased POS-1 cell proliferation in the presence of $0.5 \%$ inactivated FCS, the maximal effect being observed at $100 \mathrm{ng} / \mathrm{ml}(-31 \%, \mathrm{p}=0.003$, Fig. 4). In parallel, the effects of RANKL were studied on POS- 1 cell phenotype modulation by the analysis of osteoblastic and osteoclastic marker expression by semi-quantitative RT-PCR. 


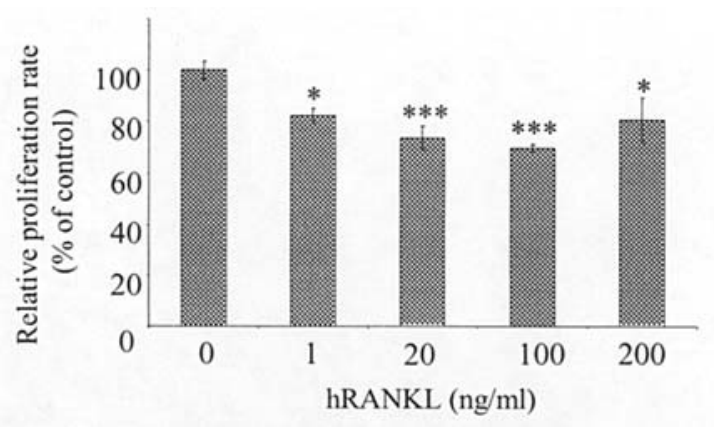

Figure 4. Effects of soluble human RANKL on POS-1 cell proliferation in vitro. POS-1 cells were seeded in a 96-well plate and cultured for $72 \mathrm{~h}$ in RPMI-1640 medium supplemented with $0.5 \%$ heat-inactivated serum in the absence or presence of human soluble RANKL at the indicated concentrations. Proliferation was measured using the XTT quick proliferation kit as described in Materials and methods. Changes in absorbance at $490 \mathrm{~nm}$ were measured and results are presented as percentage of untreated cell proliferation. ${ }^{*} \mathrm{p}<0.05,{ }^{* * *} \mathrm{p}<0.005$.
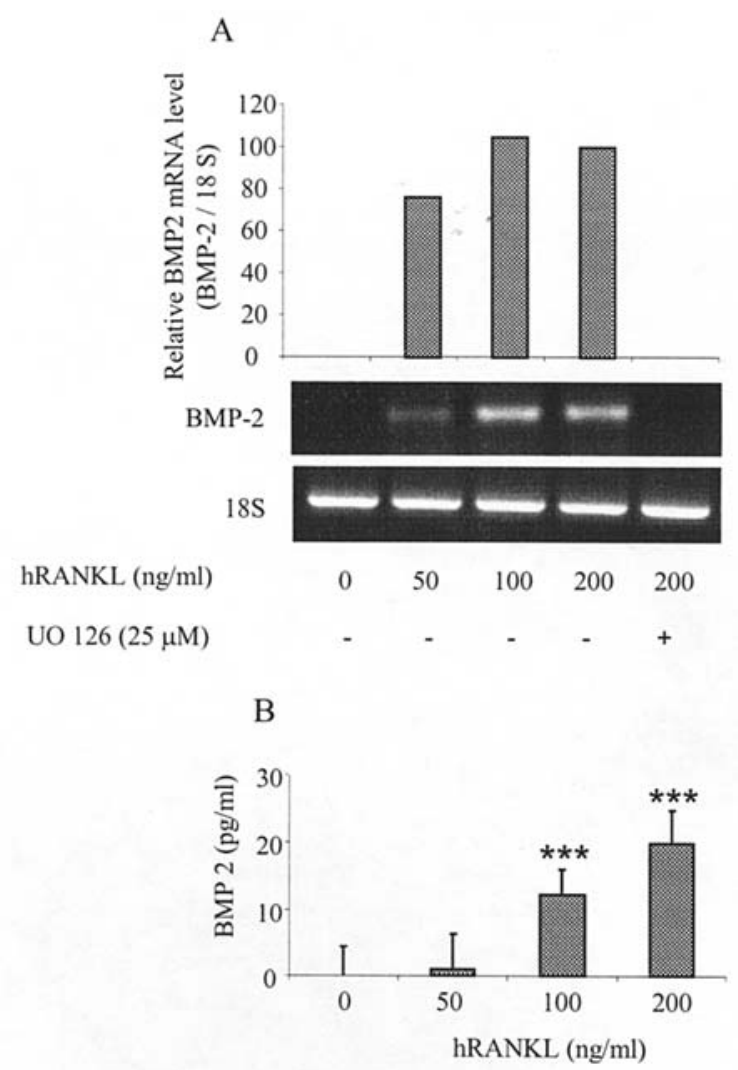

Figure 5. RANKL induces BMP-2 expression in POS-1 cells. A, relative BMP-2 mRNA levels were measured by semi-quantitative RT-PCR in POS- 1 cells treated for $6 \mathrm{~h}$ in the presence of increasing concentrations of human RANKL. In a separate experiment, pOS-1 cells were incubated with $200 \mathrm{ng} / \mathrm{ml}$ RANKL in the presence of $25 \mu \mathrm{M}$ UO 126, a synthetic inhibitor of the ERK pathway. B, ELISA assay was used to quantify BMP-2 levels in culture supernatants of POS-1 cells treated or not with increasing concentrations of RANKL for $24 \mathrm{~h} .{ }^{* * *} \mathrm{p}<0.005$.

Whereas POS-1 cells did not express BMP-2 at the mRNA level (Fig. 2), the induction of the BMP-2 transcripts was observed when these cells were cultured in the presence of $50 \mathrm{ng} / \mathrm{ml} \mathrm{hRANKL}$ for $6 \mathrm{~h}$ with a maximal effect at 100 and $200 \mathrm{ng} / \mathrm{ml}$ (Fig. 5A). The RANKL-induced BMP-2 mRNA expression was then confirmed at the protein level by ELISA, with a dose-dependent augmentation of BMP-2 in the supernatant of POS-1 treated with 50, 100 and $200 \mathrm{ng} / \mathrm{ml}$ RANKL (respectively $1.83,12.66$ and $19.05 \mathrm{pg} / \mathrm{ml}$; Fig. 5B). The expression of other bone markers was not significantly modified by RANKL treatment (not shown). The ability of RANKL to induce mineralization nodules was further tested in vitro to ascertain whether this factor may induce other activities in POS-1 cells related to enhanced osteogenic potential. The results revealed no induction of mineralization nodules in POS-1 cells (not shown).

RANKL-induced BMP-2 expression depends on ERK signalling pathways. As RANKL was shown to induce biological activities in POS-1 cells, Western blot analysis was performed to determine the signalling pathways involved in these effects. p38, ERK $1 / 2$ and IкB, the three most reported signalling pathways for RANKL were analysed (13). The results revealed a specific induction of the phosphorylated ERK 1/2 form after 5-, 10- and 15-min incubation with $100 \mathrm{ng} / \mathrm{ml} \mathrm{hRANKL}$ (Fig. 6), as compared to the total protein (not shown). The phosphorylation signal then returned to basal level after an incubation period of $30 \mathrm{~min}$ in the presence of RANKL. A weaker induction of IкB and p38 phosphorylations was also observed after 5 and 10-15 min of incubation with hRANKL respectively (Fig. 6). As ERK seemed to be the major transduction pathway activated by RANKL in POS-1 cells, the effect of a synthetic ERK inhibitor, UO 126, has been studied in the RANKL-induced BMP-2 expression. The results showed a specific blockade of RANKL-induced BMP-2 expression in the presence of $25 \mu \mathrm{M}$ UO 126 (Fig. 5A).

Collectively, these results demonstrate that soluble RANKL acts on POS-1 cells by inducing BMP-2 mRNA and protein expression through the ERK-dependent signalling pathway.

RANKL-induced BMP-2 expression has no effect on POS-1 cell behaviour in vitro. To determine whether RANKLinduced BMP-2 expression may alter POS-1 cell behaviour, the effects of hBMP-2 (1-100 ng/ml) were assessed in vitro by proliferation test, caspase- 3 activation or alkaline phosphatase activity. Using the XTT-based method, 1-100 ng/ml hBMP-2 did not significantly modify the POS-1 cell proliferation (not shown). As this factor has been described as promoting osteoblast cell death (14), we analysed the effects of hBMP- 2 on caspase- 3 activity in POS- 1 cells. The results showed a weak up-regulation of caspase- 3 activity in the presence of 10 and $50 \mathrm{ng} / \mathrm{ml}$ BMP-2 for $72 \mathrm{~h}$, which was not significant ( $+5.8 \%$ and $5.9 \%$ respectively, not shown). To see whether BMP-2 may modify POS-1 cell biological activity, alkaline phosphatase activity was studied in the presence of 1-100 ng/ml hBMP-2 for 24-72 h. No induction of alkaline phosphatase activity could be detected in POS-1 cells in the presence of BMP-2 (not shown), as observed in the presence of RANKL (Fig. 2).

RANKL-induced BMP-2 expression in osteosarcoma POS-1 cells is RANK-dependent. To demonstrate that cell surface RANK expressed by POS-1 cells is involved in the RANKLinduced BMP-2 expression, we blocked the RANKL activity 


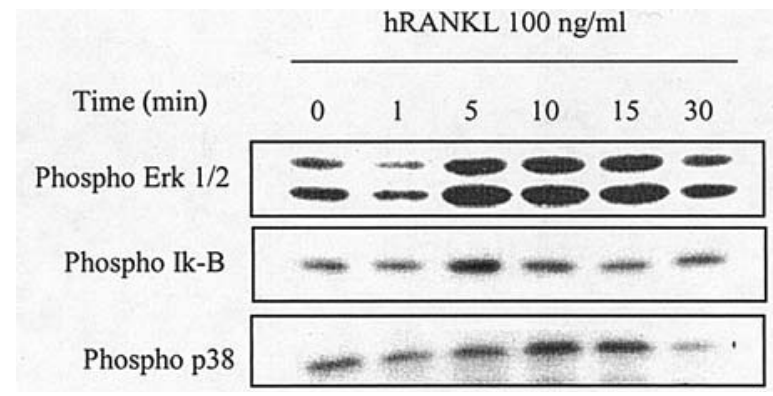

Figure 6. RANKL induces signal transduction pathways in POS-1 cells. At $70-80 \%$ confluence, pOS- 1 cells were serum-starved for $24 \mathrm{~h}$ and then incubated for $1,2,5,10,15$ and $30 \mathrm{~min}$. in the absence or presence of $100 \mathrm{ng} /$ $\mathrm{ml}$ human RANKL. Aliquots of whole cell lysates were analysed by immunoblotting for phospho-ERK 1/2phospho IкB and phospho p38.

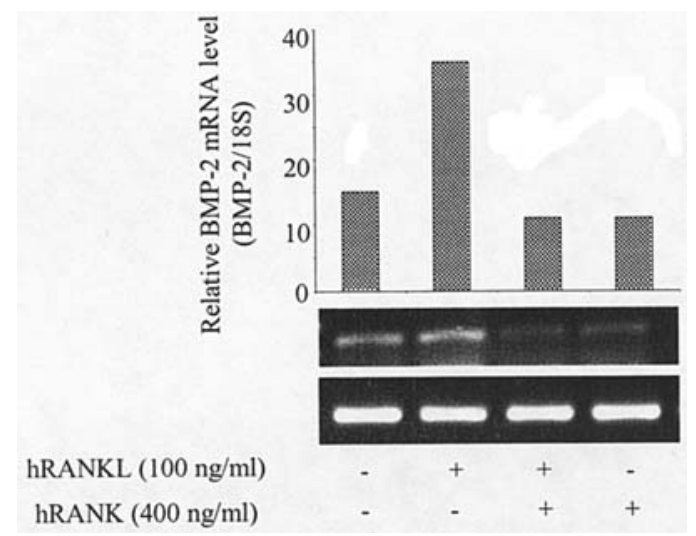

Figure 7. RANKL-induced BMP-2 expression in POS-1 cells is inhibited by soluble RANK. At 70-80\% confluence, pOS-1 cells were treated for $6 \mathrm{~h}$ with $100 \mathrm{ng} / \mathrm{ml} \mathrm{hRANKL}$ that was first pre-incubated for $1 \mathrm{~h}$ with $400 \mathrm{ng} / \mathrm{ml}$ human soluble RANK (2-fold molar excess). Relative BMP-2 mRNA levels were measured by semi-quantitative RT-PCR and corrected with the $18 \mathrm{~S}$ mRNA levels. A representative experiment is shown.

with an excess of soluble RANK by preincubating $100 \mathrm{ng} / \mathrm{ml}$ hRANKL with increasing concentrations of human RANK before adding to POS-1 cells. The results presented in Fig. 7 showed a complete inhibition of RANKL-induced BMP-2 expression in the presence of a two-fold molar excess of soluble hRANK.

\section{Discussion}

A comprehensive multidisciplinary approach has transformed osteosarcoma from a disease with a modest long-term survival to one in which $50-70 \%$ of patients will be cured. Unfortunately, some groups of patients who present with overt metastatic disease, patients with tumors that recur after treatment or that show low degrees of necrosis after administration of chemotherapy, remain at high risk of eventual relapse and continue to have an unsatisfactory outcome. These patients may benefit from future investigations into novel agents, such as biological response modifiers, anti-angiogenesis factors or growth receptor modulation. There is an obvious need for an adequate model for the study of osteosarcoma pathophysiology and to investigate important problems related to the therapeutics of human bone tumors.
Permanent osteosarcoma cell lines represent an important tool for the study of primary bone tumors. The POS- 1 cell line is derived from osteosarcoma which developed spontaneously in $\mathrm{C} 3 \mathrm{H}$ mice and parallels with humans clinical data, leading to spontaneous metastasis to the lungs (10). This experimental model was used in the present study to evaluate cellular characteristics in vitro and then correlate them with the in vivo comportment of the tumor. Conventional osteosarcomas are classified as fibroblastic, chondroblastic or, more often, osteoblastic, depending on the predominant cellular component. However, Narita et al demonstrated that several tumor cell lines can loose some of their properties when cultured for a long time in vitro (9). Another study from Yoshikawa et al demonstrated that HMOS-1, a human mandibular osteosarcoma cell line with an osteoblastic phenotype, could induce osteoid formation and ALP activity but did not express collagen I (15). Taking advantage of our osteosarcoma model, both at the in vitro and in vivo level, we wanted to characterize these cells in vitro in relation with the in vivo behavior of the tumor. In our model, POS-1 osteosarcoma cells express very few osteoblastic markers: OPG and the transcription factor, Cbfa1, predominantly described in cells of the osteoblast lineage (16), but not osteocalcin, Bone SialoProtein, BMP-2 or RANKL, and they show no ALP activity. In fact, POS-1 osteosarcoma cells exhibit an undifferentiated phenotype. This is in agreement with the well-described characteristics of tumor cells showing an undifferentiated state associated with a high proliferative capacity, as POS-1 cells were shown to highly proliferate in vitro. Moreover, these tumor cells express specific tumor antigens, such as SART3 (not shown), and still exert tumorigenicity as they induce pulmonary metastatic lesions when re-injected into mice, and they also induce bone destruction in vivo contiguously to the tumor itself. It appears, therefore, that osteosarcoma POS-1 cells in culture express an undifferentiated phenotype but keep their capacity to induce tumor growth and bone destruction in vivo. In humans, osteosarcomas frequently penetrate and destroy the cortex of the bone and extend into the surrounding soft tissue. The unifying histological feature present in all types and subtypes of OS is the presence of malignant osteoid produced by the neoplastic cells (2). As POS-1 cells express some 'osteoclast' markers in vitro (TRAP, Cat $\mathrm{K}$ and RANK) and induce bone destruction in vivo, one can suggest that mouse POS-1 osteosarcoma is more osteolytic than osteosclerotic. It can be hypothesized that POS-1 cells can induce osteolytic lesions, as they express cathepsin K and MMP-9 mRNA, two major enzymes involved in bone destruction (17).

However, the expression of TRAP and RANK is not restricted to osteoclasts as TRAP has been already described in osteoblast-like cells (18) including osteosarcoma (19). RANK expression has been described in osteosarcoma-derived cell lines (20) together with bone marrow stromal cells and osteoblasts (21). Cathepsin K, a cysteine protease expressed by osteoclasts, appears to be essential for osteoclast-mediated collagen type-I degradation (22). Cathepsin $\mathrm{K}$ is also expressed in breast cancer cells (23), and Brubaker et al have recently detected cathepsin $\mathrm{K}$ and its proteolytic activity in prostate cancer tissue and cell lines (24). Therefore, it can be hypothesized that cathepsin $\mathrm{K}$ expressed directly by osteosarcoma 
cells participates in the development of osteolytic lesions observed in our POS-1 model.

The OPG/RANK/RANKL triad is an important therapeutic axis in pathologies involving a dysregulation in bone remodelling, including tumor-associated osteolysis (4). A number of studies provide evidence for the direct production of RANKL by tumor cells themselves, as reported in multiple myeloma (25), prostate cancer (26), carcinoma cell lines (6) or human neuroblastoma (27). RANKL can then bind to its cognate receptor, RANK, at the surface of osteoclast precursors acting directly on osteoclast differentiation and activation. In the present POS-1 osteosarcoma model, POS-1 cells express RANK, not RANKL. RANK is known to be predominantly present at the surface of osteoclasts and some immune cells (28), but its expression has also been revealed in marrow stromal cells and osteoblasts and was strongly up-regulated when activated by T-cell conditioned medium (21). Another publication from Miyamoto et al reported that human osteosarcoma-derived cell lines expressed both RANK and RANKL mRNAs but the functionality of the receptor, RANK, was not investigated (20). However, the presence of a functional receptor, RANK, at the surface of cancer cells is in agreement with the results of Tometsko et al who recently reported the direct effects of RANKL on RANK-expressing human breast cancer cells, MDA-MB-231, and prostate PC3 (29). They demonstrated that RANKL treatment of both MDA-231 and PC3 cells led to the activation of signal transduction pathways (p38 MAPK, p42/44 MAPK, NF-кB) and upregulated the expression of 194 mRNA as assessed by micro-array. From these data, we can hypothesize that, while neither cell line (MDA-231, PC3 and POS-1) expresses RANKL in vitro, it is probable that the locally increased RANKL within the bone microenvironment could activate tumor cell-expressed RANK in a paracrine manner.

In our experimental model, RANKL decreased POS-1 cell proliferation and induced the expression of BMP-2 through its receptor, RANK, expressed on osteosarcoma cells. The in vitro induction of BMP-2 by RANKL does not reflect an enhancement of the osteogenic properties of the cells, as mineralization was not induced by RANKL, nor expression of other bone anabolic molecules. BMPs are a group of related proteins which are capable of inducing the formation of cartilage and bone, but are now regarded as multifunctional cytokines. A study by Hay et al (14) demonstrated that BMP-2 promoted apoptosis in primary human calvaria osteoblasts by increasing the $\mathrm{Bax} / \mathrm{Bcl}-2$ ratio, the release of cytochrome $c$ to the cytosol and caspase- $9,-3,-6$ and -7 activity. As BMP-2 induces apoptosis in myeloma cell lines and primary samples from patients with multiple myeloma in vitro, it has been suggested that this cytokine may have the potential to be a novel therapeutic agent for the treatment of patients with multiple myeloma (30). As BMP-2's receptors have been described on several cancer cell lines, its effects as an anticancer drug is now emerging (31). However, in the present study, BMP-2 did not induce POS-1 cell apoptosis nor modulate POS-1 cell proliferation. Therefore, further study is needed to explore the potential biological activity of BMP-2 in osteosarcoma.

The RANK signalling mechanisms involved in RANKL responses have been well described and include the recruitment of TNF receptor-associated factor proteins, the activation of transcription factors (NF-kB, AP-1, and NFAT2), the cascades of mitogen-activated protein kinases (ERK, JNK, and p38), and the induction of Src- and phosphatidylinositol 3-kinasedependent Akt activation (13). In the present study, RANKL predominantly induced ERK phosphorylation with a weak activation of NF- $\kappa \mathrm{B}$ and p38 signalling pathways. As synthetic inhibition of the ERK pathway totally blocked the RANKLinduced BMP-2 expression in POS-1 cells, this signal transduction pathway seemed to be the major pathway activated by RANKL through its receptor, RANK, at the surface of osteosarcoma cells, whereas NF-kB and p38 pathways were less involved.

This study describes for the first time the presence of a functional receptor RANK at the surface of osteosarcoma cells, that may mediate the establishment of osteolytic lesions induced by the tumor in vivo. Targeting RANKL/RANK interaction by the use of OPG or soluble RANK may offer new therapeutic approaches for osteosarcoma, as it has for other malignant osteolytic pathologies (32).

\section{Acknowledgements}

This work was supported by the Ministère de la Recherche (ACI no. TS/0220044) and the 'Comité des Pays de Loire de la Ligue Contre le Cancer' (K. Mori received a fellowship from the 'Ligue Nationale Contre le Cancer'). We thank P. Pilet from the microscopy platform and C. Bailly, A. Hivonnait and C. Le Corre from the Experimental Therapy Unit platform of the IFR26 (Nantes, France) for their technical assistance.

\section{References}

1. Klein ML, Kenan S and Lewis MM: Osteosarcoma: clinical and pathological considerations. Orthop Clin North Am 20: 327-345, 1989.

2. Weiss SW and Goldblum JR: Enzinger and Weiss' Soft Tissue Tumors. 4th edition. Mosby, St. Louis, MO, 2001.

3. Tsuchiya H, Kanazawa Y, Abdel-Wanis ME, et al: Effect of timing of pulmonary metastases identification on prognosis of patients with osteosarcoma: the Japanese Musculoskeletal Oncology Group study. J Clin Oncol 20: 3470-3477, 2002.

4. Theoleyre S, Wittrant Y, Kwan Tat S, Fortun Y, Rédini F and Heymann D: The molecular triad OPG/RANK/RANKL: involvement in the orchestration of pathophysiological bone remodelling. Cytokine Growth Factor Rev 15: 457-475, 2004.

5. Grimaud E, Soubigou L, Couillaud S, et al: Receptor activator of $N F-\kappa B$ ligand (RANKL)/osteoprotegerin (OPG) ratio is increased in severe osteolysis. Am J Pathol 163: 2021-2031, 2003.

6. Huang L, Cheng YY, Chow LTC, Zheng MH and Kumta SM: Tumour cells produce receptor activator of $N F-\kappa B$ ligand (RANKL) in skeletal metastases. J Clin Pathol 55: 877-878, 2002.

7. Thomas RJ, Guise TA, Yin JJ, et al: Breast cancer cells interact with osteoblasts to support osteoclast formation. Endocrinology 140: 4451-4458, 1999.

8. Chirgwin JM and Guise TA: Molecular mechanisms of tumorbone interactions in osteolytic metastases. Crit Rev Eukaryot Gene Expr 10: 159-178, 2000.

9. Narita T, Kawakami-Kimura N, Sato M, et al: Alteration of integrins by heparin-binding EGF-like growth factor in human breast cancer cells. Oncology 53: 374-381, 1996.

10. Kamijo A, Koshino T, Uesugi M, Nitto H and Saito T: Inhibition of lung metastasis of osteosarcoma cell line POS-1 transplanted into mice by thigh ligation. Cancer Lett 188: 213-219, 2002.

11. Wittrant Y, Theoleyre S, Couillaud S, Dunstan C, Heymann D and Rédini F: Relevance of an in vitro osteoclastogenesis system to study receptor activator of $\mathrm{NF}-\kappa \mathrm{B}$ ligand and osteoprotegerin biological activities. Exp Cell Res 293: 292-301, 2004. 
12. Chipoy C, Berreur M, Couillaud S, et al: Down-regulation of osteoblast markers and induction of the glial fibrillary acidic protein by Oncostatin $\mathrm{M}$ in osteosarcoma cells require $\mathrm{PKC} \delta$ and STAT3. J Bone Miner Res 19: 1850-1861, 2004.

13. Lee ZH and Kim H-H: Signal transduction by receptor activator of nuclear factor kappa B in osteoclasts. Biochem Biophys Res Commun 305: 211-214, 2003.

14. Hay E, Lemonnier J, Fromigue O and Marie PJ : Bone morphogenetic protein-2 promotes osteoblast apoptosis through a smadindependent, protein kinase C-dependent signaling pathway. J Biol Chem 276: 29028-29036, 2001.

15. Yoshikawa H, Ohishi M, Kohriki S, Yoshiura M and Ohsaki Y: Establishment and characterisation of an osteoblastic clonal cell line from human mandibular osteosarcoma (HMOS-1). Oral Oncol 33: 163-168, 1997.

16. Ducy P, Zhang R, Geoffroy V, Ridall AL and Karsenty G: Osf2/Cbfa1: a transcriptional activator of osteoblast differentiation. Cell 89: 747-754, 1997.

17. Delaissé J-M, Andersen TL, Engsig MT, Henriksen K, Troen T and Blavier L: Matrix metalloproteinases (MMP) and Cathepsin K contribute differently to osteoclastic activities. Microsc Res Tech 61: 504-513, 2003.

18. Masuda R, Sakiyama H, Nonaka T, et al: Establishment and characterization of tartrate-resistant acid phosphatase and alkaline phosphatase double positive cell lines. Cell Tissue Res 304: 351-359, 2001.

19. Olstad OK, Gautvik VT, Reppe S, et al: Molecular heterogeneity in human osteosarcoma demonstrated by enriched mRNAs isolated by directional tag PCR subtraction cloning. Anticancer Res 23: 2201-2216, 2003.

20. Miyamoto N, Higuchi Y, Mori K, et al: Human osteosarcomaderived cell lines produce soluble factor(s) that induces differentiation of blood monocytes to osteoclast-like cells. Int Immunopharmacol 2: 25-38, 2002.

21. Rifas L, Arackal S and Weitzmann MN: Inflammatory T cells rapidly induce differentiation of human bone marrow stromal cells into mature osteoblasts. J Cell Biochem 88: 650-659, 2003.
22. Kafienah W, Bromme D, Buttle DJ, Croucher LJ and Hollander AP: Human cathepsin K cleaves native type I and II collagens at the N-terminal end of the triple helix. Biochem $\mathrm{J}$ 331: 727-732, 1998

23. Littlewood Evans AJ, Bilbe G, Bowler WB, et al: The osteoclastassociated protease cathepsin $\mathrm{K}$ is expressed in human breast carcinoma. Cancer Res 57: 5386-5390, 1997.

24. Brubaker KD, Vessella RL, True LD, Thomas R and Corey E: Cathepsin $\mathrm{K}$ mRNA and protein expression in prostate cancer progression. J Bone Miner Res 18: 222-230, 2003.

25. Croucher PI, Shipman CM, Lippitt J, et al: Osteoprotegerin inhibits the development of osteolytic bone disease in multiple myeloma. Blood 98: 3534-3540, 2001.

26. Zhang J, Dai J, Qi Y, et al: Osteoprotegerin inhibits prostate cancer-induced osteoclastogenesis and prevents prostate tumor growth in the bone. J Clin Invest 107: 1235-1244, 2001.

27. Michigami T, Ihara-Watanabe M, Yamazaki M and Ozono K: Receptor activator of nuclear factor kappaB ligand (RANKL) is a key molecule of osteoclast formation for bone metastasis in a newly developed model of human neuroblastoma. Cancer Res 61: 1637-1644, 2001.

28. Hsu H, Lacey DL, Dunstan CR, et al: Tumor necrosis factor receptor family member RANK mediates osteoclast differentiation and activation induced by osteoprotegerin ligand. Proc Natl Acad Sci USA 96: 3540-3545, 1999.

29. Tometsko M, Armstrong A, Miller RE, et al: RANK ligand directly induces osteoclastogenic, angiogenic, chemoattractive and invasive factors on RANK-expressing human cancer cells MDA-MB-231 and PC3. J Bone Miner Res 19: S25, 2004.

30. Kawamura C, Kizaki M and Ikeda Y: Bone morphogenetic protein-2 (BMP-2) induces apoptosis in human myeloma cells. Leuk Lymphoma 43: 635-639, 2002.

31. Soda H, Raymond E, Sharma S, et al: Antiproliferative effects of recombinant human bone morphogenetic protein-2 on human tumor colony-forming units. Anticancer Drugs 9: 327-331, 1998.

32. Wittrant Y, Théoleyre S, Chipoy C, et al: RANKL/RANK/OPG: new therapeutic targets in bone tumours and associated osteolysis. Biochim Biophys Acta Rev Cancer 1704: 49-57, 2004. 